\title{
Assessoria Secretarial: Atuação na Atualização da Matriz Curricular do Curso de Graduação de Ciências da Administração de uma IES Pública Federal
}

\author{
Amanda Cristina Grasel \\ Universidade Federal de Santa Catarina (UFSC), Brasil \\ ppgsec@contato.ufsc.br \\ Cibele Barsalini Martins \\ Universidade Federal de Santa Catarina (UFSC), Brasil \\ cibele.martins@ufsc.br \\ Katia Denise Moreira \\ Universidade Federal de Santa Catarina (UFSC), Brasil \\ katia.denise@ufsc.br \\ Maria Gabriela Gheller \\ Universidade Federal de Santa Catarina (UFSC), Brasil \\ mariaggheller@gmail.com \\ Altieres de Oliveira Silva \\ Universidade Nove de Julho (UNINOVE), Brasil \\ altieres@uninove.br
}

\section{RESUMO}

Nas últimas décadas, a globalização incutiu profundas mudanças no mercado de trabalho e essa nova realidade pressionou as instituições de ensino a formularem suas matrizes curriculares com uma frequência maior, para atender às novas demandas inerentes à formação profissional do acadêmico. Dessa maneira, neste estudo, o objetivo é verificar como o profissional de Secretariado Executivo pode assessorar a Coordenação do curso de graduação em Ciências da Administração da Universidade Federal de Santa Catarina (UFSC), na atualização do currículo do curso. No que se refere aos métodos e às técnicas de pesquisa, o estudo adota a abordagem qualitativa e é descritivo quanto aos objetivos. No que se refere à estratégia, é um estudo de caso, que utilizou como técnicas de coleta de dados a bibliográfica, a documental e a observação participante. O processo de assessoria foi realizado em quatro etapas, a quais tinham como objetivo comparar matrizes curriculares de cursos de excelência de graduação em Administração com a matriz do curso de administração da UFSC, a fim de identificar elementos 


\section{FutureJournal}

FUTURE STUDIES RESEARCH JOURNAL: TRENDS AND STRATEGIES
ReVista ofiCial do PROgRama de Mestrado Profissional EM Gestão de Negócios do Profuturo - Programa de Estudos DO FUTURO - DA FIA BUSINESS SCHOOL

Editora Científica: Renata Giovinazzo Spers

Editor Internacional: James Terence Coulter Wright Editor de Relato Técnico: Daniel Estima de Carvalho Avaliação: Double Blind Review, pelo SEER/OJS Revisão: Gramática, normativa e de layout

Recebido em: 31/07/2017 Aprovado em: 28/02/2018

diferenciadores. Ao fim dos trabalhos, identificou-se que a matriz curricular não pode ser utilizada como base única para atualização do curso da UFSC, visto que não foram encontradas diferenças consideráveis entre os currículos. Desse modo, acredita-se que o fato de as demais instituições estarem ranqueadas com pontos superiores aos da UFSC deve-se a uma combinação de fatores, dentre os quais pode ou não estar incluída a questão da matriz curricular.

PALAVRAS-CHAVE: Assessoria secretarial. Matriz curricular.

Administração.

\title{
Secretarial Assistance: Performance in Updating the Management Undergraduate Curriculum at a Public Higher Education Institution
}

\begin{abstract}
Over the last decades, globalization has brought about profound changes in the labor market and this new reality pressed Educational Institutions to formulate new curriculums with a greater frequency in order to meet these new demands inherent to academic professional training. Therefore, this study aims to verify how the Executive Secretariat professional can advise the Coordination of the undergraduate course in Administration Sciences of the Federal University of Santa Catarina (UFSC) in updating the curriculum of the course. The study has a qualitative approach and about the objectives it is characterized by a descriptive research. Regarding the strategy, it is considered as a case study, which used bibliographic, documentary and participant observation as data collection techniques. The advisory process was accomplished within four steps, which had the objective of comparing curriculum of excellent business undergraduate courses to the one used in business undergraduate course at UFSC, hoping to identify differences. At
\end{abstract}


FutureJournal

FUTURE STUDIES RESEARCH JOURNAL:

TRENDS AND STRATEGIES
Gestão de Negócios do Profuturo - Programa de Estudos

DO FUTURO - DA FIA BUSINESS SCHOOL

Editora Científica: Renata Giovinazzo Spers

Editor Internacional: James Terence Coulter Wright

Editor de Relato Técnico: Daniel Estima de Carvalho

Avaliação: Double Blind Review, pelo SEER/OJS

Revisão: Gramática, normativa e de layout

the end of the research, it was shown that the curriculum cannot be used as an unique basis to updating UFSC's undergraduate course, once considerable differences were not found. Thus, it is believed that the fact that the other institutions analyzed were ranked with superior points when compared to UFSC is due to a combination of reasons, in which the curriculum issue can or cannot be included.

KEY-WORDS: Secretarial assistance. Curriculum. Management. 


\section{INTRODUÇÃO}

Nos seus primórdios, a profissão secretarial no Brasil era caracterizada por atividades voltadas exclusivamente para áreas técnicas, as quais refletiam o perfil profissional de um executor de ordens e atividades repetitivas (Brun, Cechet \& Neumann, 2012). Com o desenvolvimento de novas tecnologias, o profissional necessitou adaptar-se a um novo cenário e sua atuação tinha como essencialidades informatizar as rotinas, otimizar o tempo para a realização de atividades de assessoramento junto ao administrador e a equipe de trabalho, além de assumir novas atividades e responsabilidades organizacionais (Faria \& Pacheco, 2013).

Seguindo um processo evolutivo, a partir do fim do século $X X$, 0 secretário começa a atuar como agente facilitador entre a empresa e os clientes externos, além de agir como gestor de relacionamentos e conflitos (D’Elia, 2000). Complementam a asserção Faria e Pacheco (2013) ao afirmarem que a profissão está em constante evolução e que o profissional busca contínua atualização e aperfeiçoamento pessoal para adaptar-se às mudanças e às expectativas do mercado. Tal fato foi também observado por Scherer, Rempel, Martins e Haetinger (2012), quando apontaram que, antigamente, se associava o profissional de secretariado com a atuação em grandes empresas, entretanto, hoje, tem-se a incorporação desse profissional em outros modelos organizacionais, principalmente, em Instituições de Ensino Superior (IES), públicas (estaduais e/ou federais) ou privadas.

Sobre o Ensino Superior, Silva (2007) comenta que esse nível de educação vem se tornando, na atualidade, um tema recorrente de debates. Inseridos nesse contexto, são discutidos assuntos como, por exemplo, a reforma universitária, a implantação das novas Diretrizes Curriculares para os cursos de graduação e, mais recentemente, a discussão sobre o novo formato das IES, intitulada de Universidade Nova, com o objetivo de flexibilizar os currículos e criar novos modelos acadêmicos (Silva, 2007).

No contexto brasileiro, a educação superior é formada por um sistema complexo e diversificado de instituições privadas e públicas, cada uma com seu rol de cursos e programas e níveis de ensino, que vão desde a graduação até a pós-graduação (Neves, 2012). Em termos de estrutura, as IES 
apresentam diversas características, entre elas, destaca-se a oferta de ensino de graduação, autonomia para abrir e extinguir cursos e transferir ou acrescer vagas nos cursos já existentes e a obrigatoriedade de manter a relação entre as atividades de ensino, pesquisa e extensão (Brasil, 2001).

Diante do ora apresentado, neste estudo, considera-se a necessidade de limitação, visto que o campo vasto para reflexões como o da educação superior direciona-se para as Coordenadorias dos Cursos de Graduação, pois, de acordo com Silva (2007), a coordenadoria é o local em que os coordenadores têm funções diversas, como, por exemplo, coordenar as ações administrativas que envolvem o curso, além de gerenciar o projeto pedagógico e elaborar a matriz curricular. No que se refere, especificamente, à matriz curricular, Souza, Salgueiro e Silva (2013) mencionam que os currículos dos cursos superiores foram elaborados na década de 1960 e que tais matrizes foram criadas de forma que contemplassem os conhecimentos básicos práticos e teóricos exigidos para a formação de um profissional.

Ainda sobre a matriz curricular, Silva (2007) comenta que, dada sua importância, deve ser elaborada de forma efetiva e atualizada quando houver necessidade. Para tanto, os coordenadores precisam dialogar com seus pares sobre a construção de tal documento. Direcionando o exposto para o campo das Ciências da Administração, o autor relata que, a partir das diretrizes curriculares estabelecidas para o curso, é necessário que a matriz curricular atente para a flexibilização e a oportunidade de inovação no ensino em nível de graduação e que tal fato é elemento favorável para a retomada das reflexões sobre a formação do administrador, particularmente, nas questões relacionadas a seu currículo.

Ao contextualizado, inserem-se a Coordenação do Curso de Graduação em Ciências da Administração da Universidade Federal de Santa Catarina (UFSC), local definido como estudo de caso, e a proposta de alinhamento entre a atuação do profissional de secretariado executivo como assessor da coordenação no que se refere à construção da matriz curricular do curso. Em outras palavras, propõe-se como problematização deste estudo o questionamento: como o profissional de Secretariado Executivo pode assessorar a Coordenação do curso de graduação em Ciências da 
Administração da Universidade Federal de Santa Catarina (UFSC), na atualização do currículo do curso?

No intuito de alcançar resposta para o questionado, tem-se como objetivo deste estudo: verificar como o profissional de Secretariado Executivo pode assessorar a Coordenação do curso de graduação em Ciências da Administração da Universidade Federal de Santa Catarina (UFSC) na atualização do currículo do curso. Este estudo justifica-se por sua importância em agregar contribuições teóricas e práticas ao âmbito do secretariado, além de auxiliar na idealização de uma matriz curricular para o curso de Ciências da Administração. Acredita-se, ainda, que o ora pesquisado estimulará outras instituições de ensino superior a fazerem a análise de suas matrizes curriculares não somente do curso de Administração, mas de todos os cursos que são oferecidos, para que assim se forneça um ensino de qualidade.

A estrutura deste trabalho é composta por cinco seções: a primeira esta, introdutória; a segunda, o referencial teórico, que discute temas sobre a história do ensino da Administração no Brasil, os ciclos dos currículos de Administração, bem como as Diretrizes Curriculares do Curso e o Secretário Executivo como assessor; na terceira seção, trata-se dos métodos e técnicas de pesquisa, cujo direcionamento segue a abordagem qualitativa e descritiva, quanto aos objetivos, e o estudo de caso, como estratégia; na quarta seção, é apresentada a análise e a discussão dos resultados; na quinta seção, apresentam-se as considerações finais, seguidas pelas referências utilizadas neste estudo.

\section{FUNDAMENTAÇÃO TEÓRICA}

\subsection{O ENSINO DA ADMINISTRAÇÃO NO BRASIL}

Antes de tratar propriamente do ensino da administração no Brasil, é preciso dizer que a composição do sistema educativo brasileiro está estruturada nestes níveis: educação infantil, ensino fundamental, ensino médio, graduação e pós-graduação (Neves, 2012). Ao se tratar, especificamente, do ensino superior, tem-se que é um grau de escolaridade 
elevado no sistema brasileiro e para alcançar tal nível deve-se comprovar a conclusão dos graus que o antecedem (Barella, 2015).

Vale ressaltar que, no Brasil, existem marcos legais que dão fundamento à educação, como a Lei de Diretrizes e Bases (LDB) e o Plano Nacional de Educação (PNE) e, em termos de estrutura da educação superior, Neves (2012) expõe que tal ensino é ministrado em estabelecimentos de ensino superior públicos ou privados, para os indivíduos já tenham completado o ensino médio ou equivalente e tenham sido aprovados em processo seletivo.

No que se refere especificamente ao ensino das Ciências da Administração, verifica-se que o berço dos primeiros cursos na área são os Estados Unidos da Amárica (EUA), com a criação, no final do século XIX, da Wharton School, no ano de 1881 (Conselho Federal de Administração [CFA], 2016). Em 1952, os EUA já formavam cerca de 50 mil bacharéis e quatro mil pós-graduados, entre mestres e doutores, por ano, em Administração, segundo o CFA (2016).

De acordo Nicolini (2003), o surgimento das primeiras escolas superiores de Administração no Brasil está relacionado com o processo de desenvolvimento do país, vivido durante os governos de Getúlio Vargas (1930 a 1945 e de 1951 a 1954). Segundo o autor, essa política requeria profissionais qualificados para conduzir as organizações públicas, bem como programas de governo e empreendimentos privados, que buscavam alcançar a racionalidade econômica. "A mudança e o desenvolvimento da formação social brasileira a partir da Revolução de 1930 demandavam a preparação de recursos humanos, na forma de técnicos e tecnólogos de várias especializações, assim como métodos de trabalho mais sofisticados" (Nicolini, 2003, p. 45).

Silva e Fischer (2008) apontam que as primeiras instituições a oferecerem o curso de Administração no Brasil foram: a) Escola Superior de Administração de Negócios (Esan), em São Paulo, em 1941; b) Escola Brasileira de Administração Pública Getúlio Vargas (Ebape/FGV), no Rio de Janeiro, em 1952; c) Faculdade de Ciências Econômicas da Universidade Federal de Minas Gerais (FCE/UFMG) em Belo Horizonte, em 1952; d) Escola de Administração de Empresas de São Paulo (EAESP/FGV), em São Paulo, no ano de 1954; e) Escola de Administração (EAUFBA), em Salvador, em 1959; f) Faculdade de Economia e Administração (FEA/USP), em São Paulo, com os 
cursos de Ciências Econômicas e Ciências Contábeis e g) Instituto de Administração (UFRGS), em Porto Alegre, em 1966.

Vale ressaltar, que a Ebape/FGV caracterizou-se por ser a primeira escola de administração pública fundada em 1952, na cidade do Rio de Janeiro, com o objetivo de atender à demanda por profissionais qualificados na área pública no país (Escola Brasileira de Administração Pública e de Empresas [Ebape], 2016). A Instituição destaca-se como pioneira na publicação de livros em administração e a utilização do sistema de crédito e matrícula por disciplina no Brasil (Ebape, 2016).

Dois anos mais tarde, seguindo as constantes mudanças sociais e demandas do mercado, foi criada em 1954, na cidade de São Paulo, a Escola de Administração de Empresas de São Paulo da Fundação Getulio Vargas (EAESP/FGV), escola de administração de empresas ou de negócios (Bertero, 2006). O autor comenta que a EAESP/FGV surgiu por meio de uma parceria entre o governo federal e o empresariado brasileiro, com o intuito de formar profissionais capazes de enfrentar os desafios e as mudanças sofridas pelo Brasil, em uma época em que o país vivenciava um período de crescimento acelerado, com o surgimento de novas tecnologias e a entrada de novas potências econômicas.

Nessa direção, Lemos e Bazzo (2011, p. 5) comentam que a Fundação Getulio Vargas estabeleceu um convênio com o governo americano, mais especificamente com a Michigan State University (MSU), com o intuito de "[...] criar cursos de administração em universidades brasileiras que contemplavam a assistência técnica para a elaboração de currículos, métodos e técnicas de ensino, instalação de bibliotecas e formação de professores, dentre outros".

Sobre tais convênios, Bertero (2006) comentou que esses processos influenciaram diretamente nos currículos iniciais da EAESP/FGV e da Faculdade de Economia e Administração da Universidade de São Paulo (FEA/USP), tanto no formato, quanto na matriz curricular dos programas de graduação em Administração que foram sendo criados a partir da década de 1960 . O autor destaca, ainda, que foram os currículos da FGV e da USP que serviram de base para a criação do currículo mínimo instituído nacionalmente pelo extinto Conselho Federal de Educação (CFE). 
Desde sua criação até os dias atuais, o curso de Administração, no Brasil, passou por um processo evolutivo que proporcionou sua expansão e popularização. Dados disponibilizados pelo Instituto Nacional de Estudos e Pesquisas Educacionais Anísio Teixeira (Inep), por meio do Censo da Educação Superior de 2015, apontam que o curso de Administração é aquele com maior número de ingressantes (267.013) no ensino superior brasileiro, além de ser o que mais registra alunos concluintes (Administradores.com, 2016).

De acordo com o publicado no website administradores.com (2016), o Censo da Educação Superior do ano de 2015 apontou que se formaram 124.986 administradores, posicionando-se à frente de cursos como Pedagogia, Direito e Ciências Contábeis. Em relação ao total de matrículas, o curso está em segundo lugar, com 766.859 alunos matriculados em instituições públicas e privadas no Brasil. Os números apontam, também, que houve um crescimento na procura pelos cursos de Administração, ao mesmo tempo em que cresce a demanda por profissionais de Administração.

\subsection{OS CICLOS DOS CURRÍCULOS DE ADMINISTRAÇÃO NO BRASIL}

Considera-se o currículo de um curso de graduação o principal elemento de um projeto pedagógico, além de ser essencial para o processo de aprendizagem nas instituições de ensino (Jesus, 2008). Para Sacristán (1999, p. 61) "[...] o currículo é a ligação entre a cultura e a sociedade exterior à escola e à educação; entre o conhecimento e a cultura herdados e a aprendizagem dos alunos; entre a teoria e a prática possível, dadas determinadas condições".

No que diz respeito ao ensino de Administração no Brasil, Braga, Olher, Reis e Oliveira (2011) e Silva e Fischer (2008) apontam que houve três ciclos bem definidos, quanto à regulação e aos currículos mínimos exigidos para a formação dos profissionais. De acordo com Pinto e Motter Júnior (2012), o primeiro ciclo foi tratado no Parecer n. ${ }^{3}$ 307, de 8 de julho de 1966, que apresenta a definição do currículo mínimo; o segundo teve início a partir do Parecer n.o 433, de 5 de setembro de 1993, que estabeleceu a criação de habilitações específicas do curso de Administração; e o terceiro, no Parecer n. ${ }^{\circ}$ 
776, de 13 de dezembro de 1997, que orienta para Diretrizes Curriculares Nacionais (DCNs) dos cursos de graduação.

Braga et al. (2011) destacam que esse currículo foi estruturado a partir do Parecer n.o 307/66, cuja redação determinava que o habilitado deveria cursar as seguintes matérias para exercício da profissão: Legislação Social, Matemática, Contabilidade, Teoria Econômica, Sociologia Aplicada à Administração, Economia Brasileira, Psicologia Aplicada à Administração, Instituições de Direito Público e Privado (incluindo noções de Ética Administrativa), Legislação Tributária, Estatística, Teoria Geral da Administração, Administração Financeira e Orçamento, Administração de Pessoal e Administração de Material. Nessa perspectiva, Oliveira, Lourenço e Castro (2015) afirmam que a regulamentação das Ciências da Administração, no contexto brasileiro, em um primeiro momento, definiu um currículo mínimo, cujo objetivo era garantir o ensino profissional aos estudantes da área.

Aprovado em 1966, o currículo mínimo profissionalizante continuou em vigor até 1993, data em que se iniciou o segundo ciclo do processo de regulamentação da profissão, por intermédio do Parecer n.o 433/93, regulamentado pela Resolução n. ${ }^{0}$ 02/93, que estabeleceu a criação de habilitações específicas ao curso de Administração. O principal objetivo da reformulação era ajustar a formação de administrador com os "[...] avanços das ciências e da tecnologia no estabelecimento de uma nova ordem" (Pinto \& Motter Júnior, 2012).

Silva e Fischer (2008) lembram que essa forma de ensino manteve-se até o final dos anos de 1990, quando se iniciaram as discussões do projeto de Lei de Diretrizes e Bases da Educação (LDB) e a construção das Diretrizes Curriculares Nacionais (DCNs). As autoras comentam, também, que tais marcos legais foram e, ainda são, os condutores da estrutura dos cursos de graduação. Destaca-se que a LDB determinou o fim da ligação entre a formação e o exercício profissional, além de estabelecer que os diplomas recebidos ao término da graduação comprovem a formação recebida por seus titulares (Silva \& Fischer, 2008).

Especificamente sobre as DCNs para o curso de graduação em Administração, Silva e Fischer (2008) explicam que elas têm o papel de retratar uma dinâmica que atenda, em todos os momentos, aos diferentes 
perfis de desempenho requeridos pela sociedade; interligar o acadêmico com as mais novas e refinadas tecnologias e exigir contínuas revisões do projeto pedagógico de um curso. Oliveira et al. (2015, p. 16) acrescentam que as DCNs "[...] têm como propósito afastar o ensino superior do engessamento do currículo mínimo e do reducionismo das habilitações, garantindo um direcionamento elementar e a definição da identidade de cada curso". Dessa maneira, os autores complementam que o objetivo é construir projetos pedagógicos flexíveis, que permitam mobilizar as competências e habilidades requeridas para o desenvolvimento da profissão ao mesmo tempo em que contemplem as necessidades da sociedade.

Dessa maneira, segundo o artigo $5^{\circ}$ da Resolução n. 0 4, de 13 de julho de 2005, direcionado os cursos de graduação em Administração, os currículos dos cursos devem conter conteúdos relacionados a formação básica, formação profissional, estudos quantitativos e suas tecnologias assim como conteúdos quantitativos e suas tecnologias (Brasil, 2005). Vale ressaltar que Braga et al. (2011) alegam que, além das disciplinas contempladas nos eixos de formação citados, as diretrizes tratam, ainda, de Atividades Complementares como disciplinas obrigatórias para a efetiva conclusão do curso. Em relação às habilidades e competências, as diretrizes curriculares para o curso de graduação em Administração dispõem que a formação superior em Administração deve:

I - reconhecer e definir problemas, equacionar soluções, pensar estrategicamente, introduzir modificações no processo produtivo, atuar preventivamente, transferir e generalizar conhecimentos e exercer, em diferentes graus de complexidade, o processo da tomada de decisão; II desenvolver expressão e comunicação compatíveis com o exercício profissional, inclusive nos processos de negociação e nas comunicações interpessoais ou intergrupais; III - refletir e atuar criticamente sobre a esfera da produção, compreendendo sua posição e função na estrutura produtiva sob seu controle e gerenciamento; IV - desenvolver raciocínio lógico, crítico e analítico para operar com valores e formulações matemáticas presentes nas relações formais e causais entre fenômenos produtivos, administrativos e de controle, bem assim expressando-se de modo crítico e criativo diante dos diferentes contextos organizacionais e sociais; $V$ - ter iniciativa, criatividade, determinação, vontade política e administrativa, vontade de aprender, abertura às mudanças e consciência da qualidade e das implicações éticas do seu exercício profissional; VI - desenvolver capacidade de transferir conhecimentos da vida e da experiência cotidianas para o ambiente de trabalho e do seu campo de atuação profissional, em diferentes modelos organizacionais, revelando-se profissional adaptável; VII - desenvolver capacidade para elaborar, implementar e consolidar projetos em organizações; VIII - desenvolver capacidade para realizar consultoria em 
gestão e administração, pareceres e perícias administrativas, gerenciais, organizacionais, estratégicos e operacionais. (Brasil, 2005)

Portanto, conforme afirmam Pinto e Motter Júnior (2012), as DCNs, em vigência para os cursos de graduação de Administração, direcionam a estrutura do currículo oferecido pelas universidades e faculdades, todavia as instituições têm autonomia para elaborar o currículo da forma que lhes convier, de acordo com seus ideais e demanda do mercado no qual estão inseridas. Braga et al. (2011, p. 61) apontam que a principal preocupação quanto à elaboração da matriz curricular para o curso de Administração é

Oferecer disciplinas básicas, instrumentais e disciplinas da formação profissional, objetivando atender às metas propostas para o curso alinhado com o perfil do egresso proposto, com as diretrizes curriculares nacionais e, principalmente, com o conjunto de técnicas metodológicas referentes à metodologia compatível com a concepção do curso.

Assim, ao se considerar o trabalho de construção das matrizes curriculares e a "liberdade" que cada instituição tem para fazê-lo, acredita-se que o profissional de secretariado possa, por suas competências, assessorar o coordenador de um curso de graduação, neste caso o de Administração, em tal atividade.

\subsection{O SECRETÁRIO EXECUTIVO COMO ASSESSOR}

O exercício de qualquer atividade no âmbito organizacional necessita de assessoria, uma vez que, considerando o fato de que os seres humanos possuem capacidade limitada no que tange ao processamento de grandes quantidades de informações, é necessário um auxílio externo que exerça essa função (Monteiro, Cecatto \& Gardin, 2015). Nonato Júnior (2009) expõe que, como o homem é um ser social, constrói seu conhecimento em parceria, podendo em algumas vezes assessorar e, em outras, ser assessorado.

O autor argumenta também que "[...] as assessorias estão presentes em toda parte, desde a gestão organizacional até as práticas dos trabalhos de campo" (Nonato Júnior, 2009, p. 154) e se definem como o ato de assessorar, ou seja, ajudar, auxiliar ou colaborar com alguém durante determinado processo, contribuindo no processamento e na análise de informações que são transformadas em conhecimento (Caldas \& Santos, 2012). Nesse panorama, 
evidencia-se que a atividade de assessoramento está presente no âmbito secretarial, uma vez que

O trabalho empírico do profissional secretário é marcado pelo ato de assessorar, seja no âmbito operacional, tático, executivo, intelectual ou interdisciplinar. Desta forma, qualquer que seja a natureza da organização ou do grupo em que participe, o profissional secretário se destaca como assessor - interligando realidades, conhecimentos, pessoas, níveis hierárquicos ou inter-relacionais (Nonato Júnior, 2009, p. 157).

Nonato Júnior (2009) apresenta também a assessoria alinhada à área secretarial sob quatro eixos básicos, conforme ilustrado no Quadro 1, a seguir.

\begin{tabular}{|l|l|}
\hline \multicolumn{1}{|c|}{ EIXO } & \multicolumn{1}{|c|}{ CARACTERIZAÇÃO } \\
\hline Assessoramento & $\begin{array}{l}\text { Assessoria Operacional - técnica e tática: ligadas às rotinas } \\
\text { secretariais, às técnicas e às tecnologias. }\end{array}$ \\
\hline Assessorexe & $\begin{array}{l}\text { Assessoria Executiva - secretário executivo como gestor do } \\
\text { conhecimento, interligando o fazer e o saber do profissional nas } \\
\text { atividades gerenciais. }\end{array}$ \\
\hline Assessorística & $\begin{array}{l}\text { Assessoria Intelectual - secretário executivo como assessor de } \\
\text { pesquisa, de produção e análise de dados, de elaboração textual e } \\
\text { discursiva e ainda na assessoria científica. }\end{array}$ \\
\hline Assessorab & $\begin{array}{l}\text { Assessoria Aberta - secretário executivo no desenvolvimento de } \\
\text { práticas secretariais que extrapolam o ambiente organizacional, } \\
\text { estabelecendo relações entre as assessorias e outras áreas do } \\
\text { conhecimento. }\end{array}$ \\
\hline
\end{tabular}

\section{Quadro 1: Quatro eixos da assessoria}

Fonte: Nonato Júnior (2009)

Ao se considerar o foco deste estudo e o exposto no Quadro 1, acreditase que o secretário, como assessor para construção da matriz curricular, insere-se no eixo Assessorexe. Nesse campo, o secretário executivo que atua na área de assessoria passa a exercer funções gerenciais, que lhe permitem ocupar mais espaço junto aos gestores e às equipes, participando diretamente nas tomadas de decisões (Camargo, Warmuth, Maito \& Angnes, 2015).

Os autores destacam, ainda, que o profissional de secretariado tornouse capaz de identificar, resolver e propor soluções para os problemas que surgem no ambiente de trabalho, de modo que houve maior reconhecimento por suas atividades, proporcionando assim a realização de uma assessoria de forma mais eficiente (Camargo et al., 2015).

Mata (2009, p. 224) comenta que "[...] o profissional de secretariado executivo ao atuar ao lado dos centros decisórios da empresa precisa ter um perfil de gerador de resultados, tendo consciência que pode gerar resultados 
indiretamente". Assim, como assessor, quando exerce funções de forma proativa, antecipa problemas e promove mudanças necessárias; responsável e comprometido com suas atividades, coloca em prática seus conhecimentos, além de sempre estar atento às mudanças tecnológicas e em busca de aperfeiçoamento (Camargo et al., 2015).

Tal afirmação correlaciona-se ao proposto por Monteiro et al. (2015) sobre a assessoria executiva desempenhada pelo profissional de secretariado, a qual se refere ao auxílio prestado à organização em forma de iniciativas e ações que visam contribuir para o desenvolvimento da organização. Diante de tal argumentação, acredita-se que o secretário, como assessor no contexto ora proposto, fornece subsídios tanto práticos, quanto teóricos para a construção de uma matriz curricular alinhada tanto aos interesses organizacionais quanto aos do mercado de trabalho e daqueles que têm interesse na formação.

\section{METÓdOS E TÉCNICAS DE PESQUISA}

Diante da gama de currículos diferentes de cursos de Ciências da Administração aplicados nas universidades e instituições de ensino superior e analisando-se aqueles das universidades consideradas de excelência, notou-se a necessidade de atualizar o currículo do curso de graduação em Administração da Universidade Federal de Santa Catarina (UFSC) e, aliado a tal ponderação, inserir-se o profissional de Secretariado como assessor para alcançar tal propósito. Assim, neste trabalho, buscou-se verificar como o profissional de Secretariado Executivo pode assessorar a Coordenação do curso de graduação em Ciências da Administração da UFSC na atualização do currículo do curso.

Dessa maneira, este estudo caracteriza-se como pesquisa de abordagem qualitativa, pois, de acordo com Gil (2012), a pesquisa qualitativa objetiva descrever as características de um fenômeno, população, ou, então, o estabelecimento de relações entre variáveis. Assim, com o auxílio do assessor, reuniu-se a matriz curricular, os planos de ensino do curso de 
graduação em Administração da UFSC e outros currículos de cursos de Administração de excelência no Brasil. Realizado o levantamento, fez-se uma comparação entre as matrizes curriculares a fim de conhecer as semelhanças e as diferenças entre aquilo que os melhores cursos ofertavam e o que a administração da UFSC oportunizava para os acadêmicos.

Quanto aos objetivos, a classificação deste estudo é descritiva, o que, segundo Gil (2002, p. 42), significa ter "[...] como objetivo primordial a descrição das características de determinada população ou fenômeno ou, então, o estabelecimento de relações entre variáveis". A pesquisa ora desenvolvida possui caráter descritivo, pois descreve a relação entre as variáveis matriz curricular dos cursos de graduação em Administração, curso de graduação em Administração da UFSC e a assessoria do SE nesse contexto.

No que se refere à estratégia, trata-se de um estudo de caso, que, de acordo com Yin (2001, p. 33), é "[...] uma investigação empírica que investiga um fenômeno contemporâneo dentro de seu contexto da vida real, especialmente quando os limites entre o fenômeno e o contexto não estão claramente definidos". Assim, foi realizado o estudo do fenômeno assessoramento, realizado por um profissional de secretariado, na construção da matriz curricular do curso de graduação em Administração da UFSC. O trabalho foi realizado entre os meses de agosto e novembro de 2016 e ocorreu em quatro etapas, as quais são descritas adiante.

Quanto à técnica de coleta de dados, este trabalho usou a técnica bibliográfica e documental. Segundo Gil (2002), os dois métodos são muito semelhantes, o que os difere é a natureza das fontes. Enquanto na pesquisa bibliográfica as fontes são constituídas principalmente de material impresso publicado em meios escritos e eletrônicos, como livros e artigos científicos e de contribuições de diferentes autores sobre o tema, a pesquisa documental baseia-se em materiais que não receberam tratamento analítico e que ainda serão analisados de acordo com os objetos da pesquisa, além de possuírem fontes muito mais diversificadas e dispersas (Gil, 2002).

Desse modo, evidenciam-se o caráter bibliográfico - em razão de ter sido necessária a construção de um arcabouço teórico sobre o ensino e os ciclos dos currículos dos cursos de Administração no Brasil, bem como sobre o Secretário Executivo como assessor nas organizações para fundamentar e 
ampliar os conhecimentos para o desenvolvimento da pesquisa - e o caráter documental, pelo fato de as referências obtidas para a realização da pesquisa serem documentos dos mais variados tipos, tais como resoluções, leis, artigos, orientações emitidas pelos organismos nacionais e dados obtidos na web.

Retomando a questão das quatro etapas da execução do trabalho, temse que, na primeira, foi feito um levantamento da matriz matricular do curso de graduação em Administração da UFSC a fim de identificar quais as disciplinas oferecidas na estrutura curricular. Em seguida, na segunda etapa, foram feitas consultas sobre autores e áreas relacionadas ao estudo, os quais discutem os temas relevantes para o desenvolvimento da pesquisa. A terceira etapa consistiu em realizar uma pesquisa para buscar rankings da educação superior no sentido de identificar instituições de referência no curso de graduação em Administração. A quarta etapa caracterizou-se por sistematizar e estruturar todos os dados coletados em tabelas e gráficos para apresentação dos resultados da pesquisa.

Os instrumentos utilizados para a coleta de dados no ambiente de estudo foram análise da matriz curricular e identificação, por meio de rankings, de instituições de referência no ensino da Administração, assim, foi analisada a estrutura curricular do curso de graduação em Administração da UFSC, com o objetivo de coletar as informações necessárias para a atualização do currículo. Outro instrumento metodológico usado para este estudo foi a observação participante, a qual Lima, Almeida e Lima (1999) afirmam ser um ponto positivo para o pesquisador, pois fornece-lhe um contato pessoal com o local pesquisado, ou seja, consiste na inserção do pesquisador no grupo observado e na atividade de assessoria, neste caso, exercida pelo profissional de secretariado executivo.

Quanto à análise dos dados, utilizou-se a estatística descritiva que, segundo Morais (2005, p. 8) envolve "um conjunto de técnicas analíticas utilizadas para resumir o conjunto de dados recolhidos numa dada investigação, que são organizados, geralmente, através de números, tabelas e gráficos". Nesse sentido, a análise se aplica, neste estudo, na decodificação e interpretação dos dados obtidos por intermédio das ferramentas já especificadas. Os resultados são apresentados na próxima seção. 


\section{APRESENTAÇÃO E ANÁLISE dOS RESULTADOS}

Ao iniciar a assessoria na coordenadoria do curso de graduação em Administração da UFSC, notou-se uma preocupação, por parte dos coordenadores, no que se refere ao tipo de formação oferecida aos futuros profissionais, com base no currículo adotado. Conforme relatado pela coordenadora, as recentes mudanças nos currículos dos cursos e a instituição das DCNs promoveram tal reflexão e, após discussões entre os pares, decidiuse por atualizar o currículo, no sentido de promover a formação de um profissional mais preparado para atuar no mercado de trabalho.

Diante de tal decisão, o primeiro passo foi mapear as atividades pertinentes à alteração curricular no curso de Administração do CAD/UFSC, e o Secretário Executivo, por sua competência em assessoria, foi designado para assumir tal função. Assim, a primeira etapa de coleta de dados consistiu em acessar o site do curso de graduação em Administração da UFSC e fazer o levantamento da matriz curricular. A intenção foi identificar componentes, tais como disciplinas oferecidas na estrutura curricular por semestre, carga horária, pré-requisitos, equivalência, caráter (obrigatória ou optativa) e área de conhecimento.

Na sequência, foram levantados os planos de ensino oficiais das disciplinas encontrados no site do Departamento de Administração e, em seguida, os planos de ensino praticados, entregues pelos professores do CAD no semestre 2016/1. Na sequência, buscaram-se rankings da educação superior, a fim de serem identificadas instituições de referência em graduação em Administração para análise de currículos.

Para busca dos rankings foram analisadas a edição 2012 do Exame Nacional de Desempenho de estudantes (Enade) e a edição 2016 do Ranking Universitário Folha (RUF). Ressalta-se que foram pesquisados somente os rankings nacionais e suas edições atuais, em razão do caráter do sistema de ensino brasileiro. Vale destacar a importância do ranqueamento acadêmico, que, segundo Ordorika e Gómez (2010), possui três características, que o legitimam: a) a primeira relaciona-se ao interesse dos estudantes em ingressar 
nas melhores IES do país; b) a segunda refere-se ao prestígio atribuído ao mercado educacional, concedido pelos rankings às IES que alcançaram o melhor desempenho; e c) a terceira diz respeito ao status e à diferenciação institucional que as IES adquirem ao se apresentarem com maior peso e importância no meio acadêmico.

Após identificação dos rankings, verificaram-se informações acerca dos critérios de classificação e os métodos de avaliação utilizados por cada um. 0 primeiro a ser pesquisado foi o Ranking Universitário Folha (RUF). De acordo com o RUF, as universidades públicas e privadas são classificadas a partir dos seguintes indicadores: pesquisa, inovação, internacionalização, ensino e mercado.

O segundo ranking analisado foi o Enade, cuja prova avalia o desempenho dos alunos concluintes dos cursos de graduação, com o objetivo de verificar conteúdos programáticos, habilidades e competências adquiridas em sua formação. As provas do Enade são aplicadas a cada três anos, aos cursos de graduação da área analisada. Os critérios nelas avaliados estão divididos em quatro etapas: a) questionário do estudante; b) questionário do coordenador(a) do curso; c) prova; e d) questionário de impressões dos estudantes sobre a prova.

Analisados os rankings, identificou-se uma instituição de referência em cada esfera: pública federal, pública estadual e particular. Para tanto, foram adotados os seguintes critérios de inclusão: melhor colocação no RUF e melhor nota no Enade. Nessa direção, no primeiro momento, foi feito o filtro das melhores universidades federais, estaduais e particulares pela colocação no RUF; em seguida, verificou-se se essas instituições constavam na classificação do Enade. Como resultado da análise dos rankings - classificação no RUF e a nota do Enade -, obteve-se o apresentado no Quadro 2, a seguir.

\begin{tabular}{|c|c|c|c|}
\hline $\begin{array}{c}\text { Nome da } \\
\text { Instituição }\end{array}$ & Posição RUF & Nota ENADE & Esfera \\
\hline Udesc & 10 & 4,77 & Estadual \\
\hline UFGRS & $1^{0}$ & 4,76 & Federal \\
\hline Ebape/FGVRJ & $3^{0}$ & 4,86 & Particular \\
\hline FGV/EAESP & $1^{0}$ & 3,38 & Particular \\
\hline
\end{tabular}

\section{Quadro 2: Classificação das Instituições}

Fonte: Elaborado pelos autores com base nos dados da pesquisa (2016) 
Observa-se, a partir do ilustrado no Quadro 2, que a Universidade do Estado de Santa Catarina (Udesc) tem a melhor classificação pelo RUF e pelo Enade, na esfera estadual, assim como a UFGRS, na federal. No âmbito particular, conforme exposto, elencaram-se duas instituições devido à disparidade nos resultados, ou seja, a Ebape/FGVRJ ficou mais bem posicionada na prova do Enade, já na classificação do RUF a mais bem colocada é a FGV/EAESP.

Definidas as instituições de referência, foram localizadas as matrizes curriculares dos cursos de graduação em Administração a fim de compará-las com as do curso de graduação da matriz da UFSC. Assim, a primeira etapa consistiu em realizar a classificação das disciplinas dos cursos de Administração conforme o Art 50 da Resolução n. ${ }^{\circ}$ 4, de 13 de julho de 2005, o qual elenca os conteúdos essenciais que devem constar nos currículos de Administração, divididos em: Conteúdos de Formação Básica, Conteúdos de Formação Profissional, Conteúdos de Estudos Quantitativos e suas Tecnologias e Conteúdos de Formação Complementar. Em seguida, objetivando-se comparar as matrizes curriculares das instituições pesquisadas com a da UFSC, elaborou-se a Figura 1, a seguir.

\begin{tabular}{|c|c|c|c|c|c|c|c|c|c|c|}
\hline \multirow{2}{*}{$\begin{array}{c}\text { Área do } \\
\text { Conhecimento }\end{array}$} & \multicolumn{10}{|c|}{ Número de Disciplinas por Instituiçâo de Ensino } \\
\hline & UFSC & $\begin{array}{l}\text { Percentual } \\
\text { sobre total }\end{array}$ & UDESC & $\begin{array}{l}\text { Percentual } \\
\text { sobre total }\end{array}$ & $\begin{array}{c}\text { EBAPE } \\
\text { FGV }\end{array}$ & $\begin{array}{l}\text { Percentual } \\
\text { sobre total }\end{array}$ & $\begin{array}{c}\text { EAESP/ } \\
\text { FGV }\end{array}$ & $\begin{array}{l}\text { Percentual } \\
\text { sobre total }\end{array}$ & UFGRS & $\begin{array}{l}\text { Percentual } \\
\text { sobre total }\end{array}$ \\
\hline Administração & 32 & $65 \%$ & 22 & $54 \%$ & 26 & $51 \%$ & 23 & $53 \%$ & 19 & $48 \%$ \\
\hline Matemática & 4 & $8 \%$ & 4 & $10 \%$ & 8 & $16 \%$ & 5 & $12 \%$ & 5 & $13 \%$ \\
\hline Social & 3 & $6 \%$ & 2 & $5 \%$ & 4 & $8 \%$ & 4 & $9 \%$ & 2 & $5 \%$ \\
\hline Contabilidade & 2 & $4 \%$ & 2 & $5 \%$ & 2 & $4 \%$ & 2 & $5 \%$ & 3 & $8 \%$ \\
\hline Direito & 2 & $4 \%$ & 4 & $10 \%$ & 1 & $2 \%$ & 3 & $7 \%$ & 4 & $10 \%$ \\
\hline Economia & 2 & $4 \%$ & 3 & $7 \%$ & 2 & $4 \%$ & 2 & $5 \%$ & 4 & $10 \%$ \\
\hline Informática & 2 & $4 \%$ & 2 & $5 \%$ & 4 & $8 \%$ & 2 & $5 \%$ & 1 & $3 \%$ \\
\hline Psicologia & 1 & $2 \%$ & 1 & $2 \%$ & 1 & $2 \%$ & 2 & $5 \%$ & 1 & $3 \%$ \\
\hline Pesquisa & 1 & $2 \%$ & 1 & $2 \%$ & 1 & $2 \%$ & 0 & $0 \%$ & 0 & $0 \%$ \\
\hline Linguistica & 0 & $0 \%$ & 0 & $0 \%$ & 0 & $0 \%$ & 0 & $0 \%$ & 1 & $3 \%$ \\
\hline História & 0 & $0 \%$ & 0 & $0 \%$ & 1 & $2 \%$ & 0 & $0 \%$ & 0 & $0 \%$ \\
\hline $\begin{array}{c}\text { Atividades } \\
\text { Complementares }\end{array}$ & 0 & $0 \%$ & 0 & $0 \%$ & 1 & $2 \%$ & 0 & $0 \%$ & 0 & $0 \%$ \\
\hline Total & 49 & $100 \%$ & 41 & $100 \%$ & 51 & $100 \%$ & 43 & $100 \%$ & 40 & $100 \%$ \\
\hline
\end{tabular}

\section{Figura 1: Distribuição das disciplinas por área}

Fonte: Elaborado pelos autores com base nos dados da pesquisa (2016)

Observa-se, primeiramente, que, na elaboração Figura 1, houve 
delimitação das disciplinas por área de conhecimento. Evidencia-se, também, que as disciplinas referentes à grande área da Administração têm papel de destaque na matriz curricular dos cursos das Instituições de Ensino pesquisadas, representam cerca da metade das disciplinas dos cursos, exceto no caso da UFSC, em que abrangência alcança 65\% das disciplinas ligadas à grande área ora discutida.

Evidencia-se, ainda, que a área de matemática apresenta a segunda maior proporção de disciplinas, com pico de 16\% na Ebape/FGV e apenas 8\% na UFSC, mesmo assim representa a segunda maior área de conhecimento do curso. Supõe-se que essa diferença ocorra em função de a UFSC ter, conforme já posto, uma concentração maior de disciplinas ligadas à área da Administração.

Em relação à área social, que abrange as disciplinas de Sociologia e Filosofia, percebe-se que todas as instituições estão preocupadas com a formação social do indivíduo na sociedade. O percentual de disciplinas nessa área varia de 5\% (Udesc e UFRGS) a 9\% a (EAESP/FGV). Quanto à área da contabilidade, percebe-se que a UFSC apresenta um dos menores percentuais de disciplinas - 4\%, idêntico ao da Ebape/FGV, entretanto, inferior aos $8 \%$ verificados na UFRGS.

No que se refere à área de Direito, percebe-se que nas instituições Udesc e UFGRS ela totaliza $10 \%$ da matriz curricular, enquanto na UFSC representa $4 \%$ e na Ebape $2 \%$. Observa-se, nesse ponto, uma discrepância no que diz respeito à oferta das disciplinas dessa linha na matriz curricular dessas IES. No que tange à disciplina de Economia, verificou-se que, na UFGRS, ela representa $10 \%$ da grade curricular, enquanto a UFSC e a Ebape apresentam os menores percentuais, de $4 \%$.

As disciplinas relacionadas à Informática e à Psicologia se fazem presentes em todas as matrizes curriculares e são consideradas, pelas instituições, disciplinas importantes para a formação do acadêmico. Outras disciplinas identificadas, como Pesquisa, Linguística, História e Atividades Complementares, não estão presentes nas matrizes curriculares de todas as instituições, fator que vai ao encontro do definido por Braga et al. (2011), quando apontam que a principal preocupação na elaboração da matriz curricular é oferecer disciplinas básicas, instrumentais e disciplinas da 
formação profissional compatíveis com a concepção do curso e com o mercado em que estão inseridas.

Diante do exposto, acredita-se que adaptar a matriz curricular de um curso de graduação, neste caso o de Administração, exige das instituições, uma criteriosa avaliação, devido às constantes mudanças vivenciadas nos dias atuais. Portanto, essa avaliação deve ser realizada no momento de incluir ou excluir disciplinas, que contemplem tanto as demandas de formação, quanto as do mercado de trabalho.

Nesse sentido, após realizada a comparação entre a matriz curricular da UFSC com as demais instituições, verificou-se que o enfoque da primeira está voltado para formação técnico-profissional, visto que contém, majoritariamente, disciplinas relacionadas à grande área da Administração. Quanto às demais instituições, observa-se, também, a predominância de disciplinas da grande área da Administração, fato que não poderia ser diferente, pois trata-se do objetivo da formação. No que se refere às demais disciplinas, não há diferenças relevantes, visto que os percentuais se assemelham.

Diante do apresentado pelos dados, acredita-se que a comparação entre as instituições pode ser utilizada como base de conhecimento, mas não como base única para atualização do curso da UFSC, visto que, conforme já dito, não há diferenças consideráveis entre os currículos. Desse modo, acredita-se que o fato de as demais instituições estarem ranqueadas com pontos superiores aos da UFSC, deve-se a uma combinação de fatores, dentre os quais pode ou não estar incluída a questão da matriz curricular.

Assim, depois de finalizado todo o trabalho de assessoria, é possível, neste momento, sugerir à coordenação que, para a atualização do currículo do curso de graduação em Administração da UFSC, é preciso buscar bases, logicamente, nas DCNs e naquilo que o mercado de trabalho local exige, mas sem deixar de pensar nacional e internacionalmente; é também importante uma pesquisa com o corpo discente, principalmente com os egressos que já estão alocados em organizações. Crê-se que o resultado de tais pesquisas, alinhados aos dados da comparação ora realizada, possa auxiliar na elaboração de uma proposta de atualização para a matriz curricular do curso ora estudado. Outras sugestões construídas após a assessoria são apresentadas nas 
considerações finais.

\section{CONSIDERAÇÕES FINAIS}

No contexto mercadológico contemporâneo, observa-se uma demanda por profissionais cada vez mais qualificados, fato que desafia as instituições de ensino a rever as estruturas curriculares dos cursos que oferecem, obrigandoas a adaptar-se às necessidades de profissionalização requeridas pelo mercado. Desse modo, neste estudo, buscou-se verificar como o profissional de Secretariado Executivo pode assessorar a Coordenação do curso de graduação em Ciências da Administração da Universidade Federal de Santa Catarina (UFSC) na atualização do curso.

Acredita-se que o objetivo tenha sido alcançado, pois, utilizando as questões levantadas por Monteiro et al. (2015) sobre a assessoria executiva, pôde-se verificar que o profissional de Secretariado está apto a auxiliar a organização em iniciativas e ações que visam contribuir para o desenvolvimento da organização. Percebeu-se, ao final do trabalho, que a assessoria do profissional de Secretariado Executivo, no mapeamento das atividades pertinentes à atualização do currículo do curso, foi essencial para o alcance dos objetivos propostos, principalmente devido a seu perfil multidisciplinar, que o capacitou para identificar, resolver e organizar as informações com qualidade. Ademais, foi possível verificar que, além de assessorar a Coordenação do Curso, o secretário atuou como um gestor do conhecimento, correlacionando o fazer e o saber no que se refere às atividades gerenciais (Nonato Júnior, 2009).

No que tange às limitações da pesquisa, ressalta-se a impossibilidade de generalização, visto que se trata de um estudo de caso. Ademais, os planos de ensino praticados pelos professores no semestre 2016/1 não foram apresentados, pois nem todos os docentes disponibilizaram os planos na coordenadoria. Tal falto impossibilitou a realização da análise das disciplinas ministradas por meio dos planos de ensino.

Por último, sugere-se, para trabalhos futuros, que as informações sejam utilizadas para uma análise comparativa mais detalhada, em que outros 
elementos também sejam levados em consideração, além das matrizes curriculares das IES de referências, visto que, conforme exposto nos resultados, além das DCNs, o mercado de trabalho de cada instituição é levado em consideração quando da elaboração da matriz curricular de cada curso. Outrossim, o resultado ora apresentado, deu origem a outras indagações que podem ser consideradas para a realização de outras pesquisas, como, por exemplo, uma vez que a matriz curricular da UFSC possui uma porcentagem maior de disciplinas voltadas para a área de Administração, quais elementos impediram o curso de estar em primeiro lugar nos rankings? 


\section{REFERÊNCIAS}

Administradores.com. (2016, 6 de outubro). Administração é o maior curso do Brasil em número de ingressantes, aponta INEP. Recuperado em 20 de dezembro, 2016, de http://www.administradores.com.br/noticias/academico/administracao-eo-maior-curso-do-brasil-em-numero-de-ingressantes-aponta-inep/114111

Barella, T. (2015). Estrutura e funcionamento do ensino superior brasileiro Paulo Nathanael P. Souza. Recuperado em 10 de dezembro, 2016, de https://pt.scribd.com/doc/61089595/Estrutura-e-Funcionamento-DoEnsino-Superior-Brasileiro-1

Bertero, C. O. (2006). Ensino e pesquisa em Administração. GVPesquisa. Recuperado em 10 de outubro, 2016, de http://gvpesquisa.fgv.br/sites/gvpesquisa.fgv.br/files/publicacoes/Ensino $\% 20$ e\%20Pesquisa\%20em\%20Administra\%C3\%A7\%C3\%A3o.pdf

Braga, G. B., Olher, B. S., Reis, F. N. S. C., \& de Oliveira, A. R. (2011). Análise da formação curricular dos cursos de administração oferecidos por instituições federais na Zona da Mata mineira à luz da resolução CNE/CES n 4 de 13 de julho de 2005. Revista Administração em Diálogo - RAD, 13(3). Recuperado em 10 de outubro, 2016, de https://revistas.pucsp.br/index.php/rad/article/viewFile/7796/5688

Brasil. (2001). Decreto no 3.860, de 9 de julho de 2001. Recuperado em 10 de outubro, 2016, de https://www.planalto.gov.br/ccivil_03/decreto/2001/d3860.htm

Brasil. (2005). Resolução no 4, de 13 de julho de 2005. Recuperado em 15 de dezembro, 2016, http://portal.mec.gov.br/cne/arquivos/pdf/rces004_05.pdf

Brun, A., Cechet, G., \& Neumann, S. (2012). Gestão secretarial: a evolução das funções do profissional de secretariado e a efetividade da inteligência emocional nos processos de trabalho. Revista do Secretariado Executivo, 8(8), 36-51. Recuperado em 17 de dezembro, 2016, de http://www.upf.edu.br/seer/index.php/ser/article/view/3024/2030

Caldas, J. B., \& Santos, M. F. S. (2012). As ferramentas da prática da gestão secretarial utilizadas pelos profissionais de secretariado executivo egressos na Universidade do Estado do Pará. Revista do Secretariado Executivo, 8, 62-74. Recuperado em 17 de dezembro, 2016, de http://www.seer.upf.br/index.php/ser/article/view/3026/2032

Camargo, M., Warmuth, D., Maito, E. A., \& Angnes, J. S. (2015). O perfil do profissional de secretariado executivo frente às organizações que praticam a responsabilidade social. Revista Capital Científico-Eletrônica - RCCe, 13(2), 96-111. 
Conselho Federal de Administração. (2016). História da profissão. Recuperado em 10 de 2016, de http://www.cfa.org.br/administracao/historia-da-profissao

D’Elia, M. E. S. (2000). Perfil atual do profissional do secretariado. Recuperado em 10 de 2016, de http://www.fenassec.com.br/c_artigos_perfil_atual_profissional_secretaria do.html

Escola Brasileira de Administração Pública e de Empresas - Ebape. (2016). História. Recuperado em 9 de outubro, 2016, de http://ebape.fgv.br/institucional/historia

Faria, D. A. A., \& Pacheco, F. L. (2013). O secretário executivo e a tomada de decisão em uma instituição de ensino superior do estado de Sergipe. Revista de Gestão e Secretariado, 4(1), 104-125. Recuperado em 9 de outubro, 2016, https://www.revistagesec.org.br/secretariado/article/view/141/pdf

Gil, A. C. (2002). Como elaborar projetos de pesquisa (4a ed.). São Paulo: Atlas.

Gil, A. C. (2012). Como classificar as pesquisas? Recuperado em 8 de dezembro, 2016, de http://www.ngd.ufsc.br/files/2012/04/ric_CLASSIFICAPESQUISAGIL.doc

Jesus, A. R. D. (2008). Currículo e educação: conceito e questões no contexto educacional. Recuperado em 6 de dezembro, 2016, de http://www.pucpr.br/eventos/educere/educere2008/anais/pdf/642_840.p df

Lemos, D. C., \& Bazzo, W. A. (2011). Administração como uma ciência social aplicada: integrando ciência, tecnologia e sociedade no ensino de administração. Revista Pensamento Contemporâneo em Administração, 5(3), 1-14. Recuperado em 6 de dezembro, 2016, de http://www.redalyc.org/html/4417/441742843001/

Lima, M. A. D. D. S., Almeida, M. C. P. D., \& Lima, C. C. (1999). A utilização da observação participante e da entrevista semi-estruturada na pesquisa em enfermagem. Revista Gaúcha Enfermagem, 20(n. esp.), 130-142. Recuperado em 13 de dezembro, 2016, de http://www.lume.ufrgs.br/bitstream/handle/10183/23461/000265980.pdf ?sequenc

Mata, M. A. (2009). O papel do secretário executivo na estrutura organizacional e na condução das relações humanas. In K. A. Portela, \& A. Schumacher (Orgs.), Gestão secretarial: o desafio da visão holística (pp. 221-245). Cuiabá: Adeptus.

Monteiro, C., Cecatto, Q. C., \& Gardin, D. A. O. (2015). O profissional de secretariado e a responsabilidade socioambiental: a importância da assessoria executiva. Revista de Gestão e Secretariado, 6(2), 134-157. 
Recuperado em 13 de dezembro, 2016, de http://www.redalyc.org/html/4356/435643524007/

Morais, C. M. M. (2005). Escalas de medida, estatística descritiva e inferência estatística. Recuperado em 13 de dezembro, 2016, de https://bibliotecadigital.ipb.pt/bitstream/10198/7325/1/estdescr.pdf

Neves, C. E. B. (2012). A estrutura e funcionamento do ensino superior no Brasil. Construindo um aprendizado. Recuperado em 13 de dezembro, 2016, https://construindoumaprendizado.files.wordpress.com/2012/11/aestrutura-e-o-funcionamento-do-ensino-superior-no-brasil.pdf

Nicolini, A. M. (2003, abril/junho). Qual será o futuro das fábricas de administradores? Revista de Administração de Empresas - RAE, 43(2), 4454. Recuperado em 10 de setembro, 2016, de http://www.scielo.br/scielo.php?pid=S003475902003000200003\&script=sci_arttext

Nonato Júnior, R. (2009). Epistemologia e teoria do conhecimento em secretariado executivo: a fundação das ciências da assessoria. Fortaleza: Expressão Gráfica.

Oliveira, A. I., Lourenço, C. D. S., \& Castro, G. C. (2015). Ensino de administração nos EUA e no Brasil: uma análise histórica. Revista Pretexto, 16(1), 11-22. Recuperado em 10 de setembro, 2016, de http://www.fumec.br/revistas/pretexto/article/view/1830

Ordorika, I., \& Gómez, R. R. (2010). El ranking Times en el mercado del prestígio universitario. Perfiles Educativos, XXXII(129), 8-22. Recuperado em 13 de dezembro, 2016, de http://www.scielo.org.mx/scielo.php?script=sci_arttext\&pid=S018526982010000300002

Pinto, V. R. R., \& Motter Júnior, M. D. (2012). Uma abordagem histórica sobre o ensino da administração no Brasil. Revista Pensamento Contemporâneo em Administração, 6(4), 1-28. Recuperado em 10 de setembro, 2016, de http://www.redalyc.org/pdf/4417/441742847002.pdf

Sacristán, J. G. (1999). Poderes instáveis em educação (B. A. Neves Trad.). Porto Alegre: Artmed.

Scherer, C., Rempel, C., Martins, S. N., \& Haetinger, C. (2012). Importância de um secretário executivo no preenchimento do aplicativo coleta de dados Capes. Revista de Gestão e Secretariado, 3(1), 54-67. Recuperado em 20 de dezembro, 2016, de https://search.proquest.com/openview/f20ce581b2f527c39512622f610e9 $1 \mathrm{c5} / 1$ ?pq-origsite $=$ gscholar $\& \mathrm{cbl}=1686336$

Silva, M. R., \& Fischer, T. (2008). Ensino de Administração: um estudo da trajetória curricular de cursos de graduação. Anais do Encontro da 
Associação Nacional de Pós-Graduação e Pesquisa em Administração ENANPAD, 32, Rio de Janeiro, RJ, Brasil.

Silva, T. T. D. (2007). Documentos de identidade: uma introdução às teorias do currículo (2a ed.). Belo Horizonte: Autêntica.

Souza, E. X. D., Salgueiro, M. A. D. A., \& Silva, D. S. D. (2013). Estudo comparativo das matrizes curriculares das IES de Alagoas frente ao resultado do Exame de Suficiência para Contadores. Convibra. Recuperado em 20 de dezembro, 2016, de http://www.convibra.com.br/upload/paper/2013/81/2013_81_6962.pdf

Yin, R. K. (2001). Estudo de caso: planejamento e métodos (2a ed., D. Grassi Trad.). Porto Alegre: Bookman. (Obra original publicada em 1984). 